\title{
Analyzing uterine rupture: A study from tertiary care centre of western Nepal
}

\section{Shrestha J', Shrestha R ${ }^{2}$}

1Junu Shrestha, Assistant Professor; ${ }^{2}$ Rami Shrestha, Resident; Department of Obstetrics and Gynaecology, Manipal Teaching Hospital, Pokhara, Nepal

\begin{abstract}
Background: Rupture uterus is a serious obstetric complication which if diagnosed and managed early improves foetomaternal outcome.

Objectives: To determine the frequency, causes, management aspects and foeto-maternal outcome of uterine rupture. Methods: This is a cross sectional observational study conducted in Department of Obstetrics and Gynaecology of Manipal Teaching Hospital from July 2012 to June 2015. All cases of rupture uterus, both complete as well as incomplete, diagnosed during surgery were included. Patient's demographic variables, clinical presentation, risk factors for rupture were studied. Factors related to rupture like the type, nature and site of uterine rupture were noted. The operative management, maternal and neonatal outcome of the patients was reviewed. All the information was entered in the Microsoft Excel chart sheet. Data was analyzed using simple frequencies and percentages.

Results: There were 22 cases of uterine rupture and 7987 deliveries during that period giving frequency of 2.8 rupture uterus in every 1000 deliveries. Uterine scar following previous cesarean section was the commonest (72.7\%) cause for rupture uterus. Repair was the commonest (86.4\%) surgical treatment done. There was no maternal mortality. Blood transfusion was needed two-third of the cases. Other complications were bladder injury (9.1\%), paralytic ileus (9.1\%), acute renal failure (4.5\%) and pneumonia (4.5\%). The perinatal mortality was $45.5 \%$.

Conclusion: Uterine rupture is a grave obstetric event with maternal and perinatal morbidity and commonly follows pregnancies with scarred uterus.
\end{abstract}

Key words: Cesarean section, Hysterectomy, Perinatal mortality, Uterine rupture

\section{INTRODUCTION}

$\mathrm{R}$ upture uterus is tearing of the uterine wall which can occur during pregnancy or delivery. Tear involving the uterine wall along with the visceral peritoneum extruding fetus to the peritoneal cavity is complete rupture while that with intact visceral peritoneal layer or broad ligament is referred to as incomplete rupture?

Grandmultiparity, injudicious use of oxytocin, obstructed labour following cephalopelvic disproportion or malpresentation, congenital anomalies of uterus, over distended uterus, placenta percreta are known factors predisposing to uterine rupture ${ }^{1-4}$. Presence of uterine scar following cesarean section, myomectomy and even previous uterine curettage, are other important

Address for correspondence

Dr. Junu Shrestha

Assistant Professor, Department of Obstetrics and Gynaecology

Manipal Teaching Hospital

Pokhara, Nepal

E-mail: junu152001@yahoo.com attributing causes of rupture uterus ${ }^{2,3}$. With increasing cesarean deliveries worldwide, previous scar in uterus has been emerging as a cause of uterine rupture lately ${ }^{5}$.

The occurrence of rupture uterus differs in different parts of the world. In the less and least developed countries, rupture uterus is more prevalent compared to developed countries, where it mostly follows previous cesarean section ${ }^{6}$. The prevalence of rupture uterus has come down dramatically in developed world but it still poses a significant problem in developing country like ours.

Rupture uterus is a catastrophic obstetric event leading to severe maternal and perinatal morbidity and mortality ${ }^{7-9}$. It is preventable complication of pregnancy and labour; delay in diagnosis and treatment of which can bring about adverse maternal and perinatal outcome.

This study was conducted with the aim of finding out frequency of uterine rupture, factors predisposing 
to uterine rupture, management options and foetomaternal outcome following the occurrence so that preventable measures could be proposed.

\section{METHODS}

This was a descriptive cross sectional observational study done in the department of Obstetrics and Gynaecology of Manipal Teaching Hospital, which is tertiary level referral hospital of western Nepal. It was conducted from July 2012 to June 2015 over a period of three years.

All patients managed in the centre for rupture uterus both complete as well as incomplete rupture were included in the study. Patients with suspicion of rupture uterus were followed up intraoperatively. If rupture was diagnosed during surgery, the patients were included in the study while patients without rupture were excluded. Patients diagnosed intraoperatively as rupture uterus with pre operative suspicion for rupture were also included. Rupture uterus either during antepartum or intrapartum period were included in the study. Approval was taken from the Institutional Review Board. Informed verbal consent was also taken from patients prior to collecting information.

Patients' demographic variables like age, parity, gestational age at time of rupture, state of booking were noted. The clinical presentation of the patients, risk factors for rupture was also studied. Factors related to rupture like the type, nature and site of uterine rupture were noted in preformed pro forma. The operative management, maternal and neonatal outcome of the patients was also reviewed.All the information was entered in the Microsoft Excel chart sheet. Data was analyzed using simple frequencies and percentages.

\section{RESULTS}

There were 22 cases of rupture uterus during study period of three years. There were 7987 deliveries during that period. The frequency of rupture uterus was 2.8 in 1000 deliveries. The socio-demographic aspects of the patients are presented in the following table.

Table 1: Socio-demographic aspects of patients with rupture uterus

\begin{tabular}{lcc}
\hline $\begin{array}{l}\text { Characteristics of } \\
\text { Patients }\end{array}$ & Number (N=22) & Percentage (\%) \\
\hline $\begin{array}{l}\text { Age (years) } \\
\leq 19\end{array}$ & 1 & \\
\hline $20-35$ & 17 & 7.55 \\
$\geq 35$ & 4 & 18.27 \\
\hline
\end{tabular}

Parity

\begin{tabular}{|lcc|}
\hline P 1 & 3 & 13.64 \\
\hline P 2-4 & 17 & 77.27 \\
\hline P $\geq 5$ & 2 & 9.09 \\
\hline State of Booking & & \\
\hline Yes & 5 & 22.73 \\
\hline No & 17 & 77.27 \\
\hline $\begin{array}{l}\text { Mode of previous delivery* } \\
\text { Vaginal delivery }\end{array}$ & 3 & 15.79 \\
\hline Hysterotomy & 1 & 5.26 \\
\hline Classical CS & 1 & 5.26 \\
\hline One LSCS & 12 & 63.16 \\
\hline Two LSCS & 2 & 10.53 \\
\hline
\end{tabular}

*Three patients were nulliparous. Total patients with previous delivery are out of 19 .

Clinical presentation of patients and the indications for surgery are presented in the following table.

Table 2: Clinical presentation and indication for surgery of patients with rupture uterus

\begin{tabular}{|lcc|}
\hline Characteristics & $\begin{array}{c}\text { Number } \\
\text { (N=22) }\end{array}$ & $\begin{array}{c}\text { Percentage } \\
\text { (\%) }\end{array}$ \\
\hline Clinical Presentations* & 2 & 9.09 \\
\hline $\begin{array}{l}\text { Decreased fetal movements } \\
\text { Pain abdomen }\end{array}$ & 9 & 40.91 \\
\hline Per vaginal bleeding & 7 & 31.82 \\
\hline $\begin{array}{l}\text { Labour pain } \\
\text { Fainting attack }\end{array}$ & 3 & 13.64 \\
\hline $\begin{array}{l}\text { Indications for Surgery } \\
\text { Suspected rupture }\end{array}$ & 2 & 9.09 \\
\hline $\begin{array}{l}\text { Unfavourable cervix with } \\
\text { intrauterine fetal death with } \\
\text { previous cesarean section }\end{array}$ & 1 & 54.54 \\
\hline $\begin{array}{l}\text { Transverse lie with placenta } \\
\text { previa }\end{array}$ & 1 & 4.55 \\
\hline $\begin{array}{l}\text { Antepartum haemorrhage } \\
\text { Previous hysterotomy }\end{array}$ & 4 & 4.55 \\
\hline $\begin{array}{l}\text { Previous cesarean section in } \\
\text { labour }\end{array}$ & 1 & 18.18 \\
\hline $\begin{array}{l}\text { Cephalopelvic disproportion } \\
\text { in labour }\end{array}$ & 1 & 4.55 \\
\hline
\end{tabular}

*Some patients with more than one clinical presentation.

Only about $54.5 \%$ of patients had undergone surgery with preoperative suspicion of rupture uterus. In the remaining patients, rupture has been incidentally diagnosed during cesarean section done for other indications. In $18 \%$ patients, patients were operated for 
suspicion of abruptio placenta and uterine rupture was diagnosed. The following table illustrates the causes and the characteristics of the uterine rupture.

\section{Table 3: Causes, characteristics and management of the uterine rupture}

\begin{tabular}{|c|c|c|}
\hline & $\begin{array}{l}\text { Number } \\
(\mathrm{N}=\mathbf{2 2})\end{array}$ & $\begin{array}{c}\text { Percentage } \\
(\%)\end{array}$ \\
\hline \multicolumn{3}{|l|}{ Causes of uterine rupture } \\
\hline Obstructed labour & 1 & 4.55 \\
\hline Precipitate labour & 1 & 4.55 \\
\hline $\begin{array}{l}\text { Congenital anomaly of } \\
\text { uterus }\end{array}$ & 1 & 4.55 \\
\hline Grand multiparity & 1 & 4.55 \\
\hline Misoprostol induction & 2 & 9.09 \\
\hline Previous scar & 16 & 72.71 \\
\hline \multicolumn{3}{|c|}{ Gestational age at time of rupture } \\
\hline 28-36 weeks & 10 & 45.45 \\
\hline 37-41 weeks & 12 & 54.55 \\
\hline$\geq 41$ weeks & 0 & \\
\hline \multicolumn{3}{|l|}{ Time of rupture } \\
\hline Antepartum & 8 & 36.36 \\
\hline Intrapartum & 14 & 63.64 \\
\hline \multicolumn{3}{|l|}{ Type of rupture } \\
\hline Complete & 16 & 72.73 \\
\hline Incomplete & 6 & 27.27 \\
\hline \multicolumn{3}{|l|}{ Site of rupture } \\
\hline Upper uterine segment & 4 & 18.18 \\
\hline Lower uterine segment & 17 & 77.27 \\
\hline Upper and lower segment & 1 & 4.55 \\
\hline \multicolumn{3}{|c|}{ Surgical management for rupture uterus } \\
\hline Repair & 15 & 68.18 \\
\hline Repair and sterilization & 4 & 18.18 \\
\hline Hysterectomy & 3 & 13.64 \\
\hline
\end{tabular}

Most of the patients (72\%) had history of previous scar in the uterus making presence of scar commonest cause of uterine rupture. Most of the rupture was complete (72.7\%). Involvement of the lower segment of uterus was commonly seen $(77.3 \%)$ with one case of rupture involving both upper and lower segment. In three patients with rupture of lower segment, there was extension to the vaginal and one had associated broad ligament hematoma. Repair was the commonest (68\%) surgical management done.

Maternal and perinatal morbidity of the patients with uterine rupture is presented in the following table.
Table 4: Maternal complications and perinatal outcome of patients with rupture uterus

\begin{tabular}{|lcc|}
\hline & Number (N=22) & $\begin{array}{c}\text { Percentage } \\
\text { (\%) }\end{array}$ \\
\hline Maternal complications* & 2 & 9.09 \\
\hline Bladder injury & 1 & 4.55 \\
\hline $\begin{array}{l}\text { Acute renal failure } \\
\text { Paralytic ileus }\end{array}$ & 2 & 9.09 \\
\hline $\begin{array}{l}\text { Lower respiratory tract } \\
\text { infection }\end{array}$ & 1 & 4.55 \\
\hline $\begin{array}{l}\text { Need for blood } \\
\text { transfusion for severe }\end{array}$ & 14 & 63.64 \\
haemorrhage & & \\
\hline Perinatal outcome & 12 & 54.54 \\
\hline Live birth & 7 & 31.82 \\
\hline Fresh stillbirth & 2 & 9.09 \\
\hline Macerated stillbirth & 1 & 4.55 \\
\hline Early neonatal death & & \\
\hline
\end{tabular}

*More than one complication possible in some patients

Need for blood transfusion was seen in $63.6 \%$ patients. Two patients sustained bladder injury. Perinatal loss was seen in $45.4 \%$ patients, mostly fresh stillbirths. There were two $(9.1 \%)$ macerated stillbirths. These patients had presented as intrauterine deaths and rupture uterus had been incidentally diagnosed during surgery. There was no maternal mortality following rupture uterus in this study.

\section{DISCUSSION}

Rupture uterus is one of the serious complications encountered in obstetrics that endangers the life of mother as well as fetus. The incidence has been declining in the developed countries but in developing country, it still bears a lot of burden in improving maternal and perinatal health ${ }^{6}$. In our study, the frequency of rupture uterus is 2.8 per 1000 deliveries. This was lower than the incidence in eastern Nepal where there were 8.9 uterine ruptures every 1000 deliveries ${ }^{10}$. Another study conducted in one of the largest maternity hospitals of Nepal has still lower incidence ${ }^{11}$. Difference in the incidence is due to different sites where the studies were conducted and different times when the studies were conducted. A study from India showed incidence similar to our study ${ }^{12}$. Studies from Pakistan and Nigeria had higher incidence of uterine rupture ranging from 5 to 9 per 1000 deliveries ${ }^{2,13-16}$.

In the present study, about $55 \%$ of patients had pre operative suspicion of rupture uterus. In the remaining patients, rupture uterus was an intraoperative diagnosis 
made at the time of cesarean section done for other indications. In two patients (9\%) who presented with decreased fetal movements, intrauterine death was diagnosed preoperatively. Cesarean section was done in these patients, one with indication of previous cesarean with unfavourable cervix and another as transverse lie with placenta previa though they had intrauterine fetal death. In both these patients, complete uterine rupture diagnosed only intraoperatively. Preoperative diagnosis was fallacious here as patients were stable and without abdominal pain. In $13.6 \%$ of patients, rent in the previous scar site was noted only during cesarean section. Therefore, high index of suspicion is necessary in making the diagnosis of uterine rupture.

Presence of previous scar was the commonest cause (72.7\%) of uterine rupture. Uterine rupture in scarred uterus was noted only in $19.8 \%$ and $29 \%$ in other studies done in Nepal ${ }^{10,11}$. Increasing rate of cesarean section over the period of years could be the cause as the other studies were conducted almost ten years back. More recent studies from abroad showed similar trend with presence of uterine scar as cause of rupture uterus ${ }^{12,15,16}$. Of these patients with uterine scar in the present study, $56 \%$ of rupture occurred during labour. Presence of uterine scar has been upcoming as the cause of uterine rupture lately as shown in one study ${ }^{17}$.

In countries where there is less use of contraception and large family size, obstructed labour, malpresentation and multiparity is the leading cause of rupture uterus $^{13,18,19}$. Induction with misoprostol was the second most cause in the present study. In one of these patients, misoprostol induction had been done for intrauterine fetal death in a patient who had history of persistent gestational trophoblastic disease. The other causes were precipitate labour, congenital anomaly of uterus and obstructed labour.

Most of the uterine rupture occurred during labour (64\%) and at term (54.5\%) in our study. Antepartum rupture occurred in $36.4 \%$ of patients; one in patient with congenital anomaly of uterus and other were rupture of previously scarred uterus. Majority of the patients (73\%) had complete rupture comparable to other studies $^{10-12,14,20}$. Most of the ruptures involved the lower uterine segment (77\%). One patient had involvement of upper as well as lower uterine segment. One case of rupture was associated with broad ligament haematoma and three (13.5\%) had extension to the vagina. Broad ligament haematoma and colporrhexis were reported in another study as well ${ }^{16}$.

Surgery was the mainstay of treatment. Repair with or without sterilization was the main treatment modality in this study. Hysterectomy for irreparable uterine rupture was done in $13.6 \%$ of cases. Repair was also the main mode of treatment in other studies ${ }^{10-12,13,15,16}$. All the hysterectomies were done for rupture of unscarred in our study. Similarly, study from Eastern Nepal also showed more number of hysterectomies in rupture of unscarred uterus ${ }^{10}$.

There was no maternal mortality following uterine rupture in the present study. Bladder injury (9.1\%), post operative paralytic ileus $(9.1 \%)$, acute renal failure $(4.5 \%)$ and lower respiratory tract infections (4.5\%) were complications that followed uterine rupture in the present study. Other complications like vesicovaginal fistula, febrile morbidity, urinary tract infection, disseminated intravascular coagulation as reported in other studies ${ }^{2,12}$, were not noted in our study. About twothird of the patients required blood transfusion similar to other studies ${ }^{12,16}$.One study reported need of blood transfusion in almost all the patients of uterine rupture ${ }^{15}$.

Perinatal deaths in the present study were $45.5 \%$, better compared to that of other studies. Perinatal mortality in these studies ranged from $73-90 \% \%^{2,10,11,13-16}$. One study showed similar perinatal outcome as in our study ${ }^{12}$. Improved perinatal outcome in these studies is because of more number of scar rupture in the studies. As presence of uterine scar has been an imminent cause for rupture uterus lately, reducing the number of cesarean section would diminish cases of rupture uterus. Also high index of suspicion of rupture uterus, early diagnosis and management help in improving maternal and perinatal outcome.

\section{CONCLUSION}

The incidence of uterine rupture was 2.8 per 1000 deliveries. Presence of uterine scar was the commonest cause of uterine rupture followed by use of prostaglandins for labour induction. Repair of rupture was the commonest mode of treatment. Hysterectomy was mostly required for rupture of unscarred uterus. There was no maternal mortality. Perinatal mortality was $45.5 \%$. High index of suspicion for uterine rupture, immediate management helps in minimizing maternal and perinatal morbidity and mortality 


\section{REFERENCES}

1. Ofir K, Sheiner E, Levy A, Katz M, Mazor M. Uterine rupture: Risk factors and pregnancy outcome. Am J Obstet Gynecol. 2003; 189(4):1042-1046

2. Qazi A, Akhtar Z, Khan K, Khan AH. Women health: uterus rupture, its complications and management in teaching hospital Bannu, Pakistan. Medica (Buchar) - A Journal of Clinical Medicine 2012; 7: 49-53

3. Smith JG, Mertz HL, Merrill DC. Identifying risk factors for uterine rupture. Clin Perinatol 2008; 35: 85-99

4. Ezechi OC, Mabayoje P, Obiesie LO. Ruptured uterus in South Western Nigeria: A reappraisal. Singapore Med J 2004; 45(3):113-116.

5. Zelo PC, Heffner LJ. The downside of cesarean delivery: short and long term complications. Clin Obstet Gynecol 2004: 47:386-93.

6. Hofmeyr GJ, Say L, Gulmezoglu AM. WHO systematic review of maternal mortality and morbidity: The Prevalence of uterine rupture. BJOG 2005; 112: 1221-1228

7. Revicky V, Muralidhar A, Mukhopadhyay S, Mahmood T. A case series of uterine rupture: lessons to be learnt for future clinical practice. J Obstet Gynaecol India. 2012; 62: 665-70

8. Berhe $Y$, Wall LL. Uterine rupture in resource poor countries . Obstet Gynecol Surv. 2014; 69: 695-707

9. Yap OW, Kim ES, Laros RK Jr. Maternal and Neonatal outcome after uterine rupture in labour. Am J Obstet Gynecol 2001; 184:1576-81

10. Chuni N. Analysis of uterine rupture in a tertiary center in Eastern Nepal: lessons for obstetric care. J Obstet Gynaecol Res 2006; 32(6):574-9
11. Padhye SM. Rupture of the pregnant uterus - A 20 year review. Kathmandu Univ Med J 2005; 3(3):2348

12. Sunitha K, Indira I, Suguna P. Clinical study of rupture uterus - Assessment of maternal and fetal outcome. IOSR Journal of Dental and Medical Sciences 2015; 14(3): 39-45

13. Babi S, Gul K, Gul Z, Gul P. management of patients with uterine rupture. Journal of Surgery Pakistan 2014; 19(3): 117-120

14. Rizwan N, Abbasi RM, Uddin SF. Uterine rupture, frequency of cases and fetomaternal outcome. J Pak Med Assoc 2011; 61(4): 322-24

15. Aziz N, Yousfani S. Analysis of uterine rupture at University teaching hospital Pakistan. Pak J Med Sci 2015:31(4):920-24

16. Mbamara SU, Obiechina NJA, Eleje GU. An analysis of uterine rupture at the Nnamdi Azikiwe University teaching hospital Nnewi, Southeast Nigeria. Niger J Clin Pract 2012; 15(4):448-52

17. Zeb L. Bibi S. Trends in frequency and causes of uterine rupture in a tertiary care center between year 2001 and 2011. Journal of Postgraduate Medical Institute 2013; 27(3): 317-321

18. Omole-Ohonsi and Attah. Uterine rupture: risk factors and pregnancy outcome. Gynecol Obstetric $2011 ; 1: 1$

19. Diab AE. Uterine rupture in Yemen. Saudi Med J 2005; 26(2):264-9

20. Turgut A,Ozler A, Evsen MS, Soydinc HE, Goruk NY, Karacor T, Gul T. Uterine rupture revisited: Predisposing factors, clinical features, management and outcomes from a tertiary care center in Turkey. Pak J Med Sci 2013; 29(3): 753-7 